\title{
NEOLIBERALISMO DE AUSTERIDADE, PERFORMANCE E DISSENSO
}

\author{
AUSTERITY NEOLIBERALISM, PERFORMANCE AND DISSENT
}

Ana Maria Isar dos Santos Gomes

Doutoranda em Direito na Pontifícia Universidade Católica de Minas Gerais. Mestre em Geografia (Gestão Ambiental e Territorial) pela Universidade de Brasília UnB (2013). Especialista em Direito Público pelo Instituto Brasiliense de Direito Público IDP (2008). Procuradora do Distrito Federal com atuação nas áreas de Direito Urbanístico, Ambiental e Imobiliário. Membro de Grupo de Pesquisa do Núcleo de Estudos Urbanos e Regionais da UnB vinculado ao CNPQ.

Giovani Clark

Doutor (2000), Mestre (1990) e Graduado (1986) em Direito pela Universidade Federal de Minas Gerais. Professor da Pontifícia Universidade Católica de Minas Gerais nos cursos de Graduação e Pós-Graduação (Mestrado e Doutorado) e da Faculdade de Direito da UFMG (Graduação).

\section{Resumo}

O artigo analisa o discurso de austeridade fiscal, apresentado pelo neoliberalismo como única solução para superação da crise econômica global de 2008, apesar de sua fragilidade do ponto de vista científico e do enorme sacrifício que representa para as classes sociais menos favorecidas. A pesquisa, de caráter bibliográfico e documental, utiliza como referenciais teóricos o conceito de narrativa proposto por Jean-François Lyotard e sua análise da teoria dos jogos, elaborada por Ludwig Wittgenstein. Com base nos trabalhos de Michel Foucault e Zigmunt Bauman, demonstra-se que o neoliberalismo de austeridade é uma das narrativas da pós-modernidade cujo critério de legitimação é a melhoria da performance do modelo capitalista. Tal narrativa vem se impondo sobre as demais por meio da eliminação do dissenso e da manipulação do medo existencial. Ao preponderar sobre as demais narrativas, o neoliberalismo de austeridade elimina as diferenças e torna as instituições homogêneas, em um movimento que contrapõe o princípio da eficiência ao princípio democrático. Conclui-se que a alternativa para proteger a democracia, neste momento, é o questionamento das regras do jogo pelos próprios participantes, de forma a se substituírem os lances inovativos - que melhoram a performance do sistema - por lances perturbadores, capazes de promover o dissenso e, assim, alterar as regras do jogo. Esses últimos lances dependem da afirmação de uma multiplicidade de pequenas narrativas, fundadas em códigos particulares que legitimam os jogos de linguagem nas mais diversas áreas do saber. 
Palavras-chave: Democracia. Dissenso. Legitimidade. Neoliberalismo de austeridade. Princípio da Eficiência.

\begin{abstract}
The article analyses the discourse of fiscal austerity, presented by neoliberalism as the only solution to overcome the global economic crisis of 2008 , despite a lack of scientific evidence, coupled with the enormous sacrifice that it imposes to less favored social classes. The research uses bibliographical and documentary resources. It is based on Jean-François's concept of narrative and his analyses of Ludwig Wittgenstein's theory of games. Grounded on Michel Foucault and Zigmunt Bauman's work, the article demonstrates that austerity neoliberalism is one of the narratives of postmodernity, which criterion of legitimation is the improvement of capitalist model's performance. It discusses how such narrative has prevailed over other narratives through elimination of dissent and manipulation of existential fear. As result, the austerity neoliberalism excludes the differences and turns the institutions homogeneous, in a movement that opposes the principle of efficiency to the principle of democracy. Finally, the article concludes that the alternative to protect democracy is the questioning of the rules of the game by the participants themselves, as a way to replace the innovative bids - intended to improve the system's performance - with perturbative ones, which may be able to promote dissent and change the rules of the game. These last bids depend on the assertion of a multitude of small narratives, based on particular codes that legitimize the games of language in different areas of knowledge.
\end{abstract}

Key-words: Austerity neoliberalism. Democracy. Dissent. Legitimacy. Principle of Efficiency.

\title{
1. CONSIDERAÇÕES INICIAIS
}

O cenário socioeconômico de grande parte das nações da América e Europa tem sido profundamente alterado por medidas de austeridade fiscal, apresentadas como a única receita para driblar a recessão econômica que se instalou de forma global desde a crise financeira de 2008. No Brasil, onde a crise econômica surgiu em meados de 2014, a ideia de que apenas as medidas de austeridade fiscal podem evitar o colapso das finanças públicas, promover a retomada do crescimento econômico e aumentar a oferta de empregos é difundida e aceita sem maiores debates.

Não se pretende discutir o alcance da crise econômica global iniciada em 2008, muito menos sugerir alternativas para superá-la, mas investigar como ela vem repercutindo nas democracias modernas. Em especial, este artigo busca compreender por que motivo, apesar de não haver qualquer evidência científica de que medidas de 
austeridade fiscal são adequadas para superar momentos de crise financeira, elas têm sido apresentadas nos países que enfrentam dificuldades econômicas como o único caminho possível para vencer a recessão.

A pesquisa, de caráter bibliográfico e documental, utiliza como referenciais teóricos o conceito de narrativa proposto por Jean-François Lyotard e sua análise da teoria dos jogos, de Ludwig Wittgenstein.Com base nos trabalhos de Michel Foucault e Zigmunt Bauman, investiga-se o papel do medo existencial na legitimação da narrativa que apresenta a austeridade fiscal como única saída para a crise econômica global. A partir desses pressupostos teóricos, busca-se encontrar respostas para as seguintes questões: Como se legitimam as instituições na pós-modernidade, quando as metanarrativas deram lugar a múltiplas narrativas? Qual é a função do medo existencial nesse contexto? O neoliberalismo de austeridade é capaz de levar à constituição de sociedades democráticas e justas?

$\mathrm{Na}$ primeira seção são apresentados os conceitos de narrativa e metanarrativa com o intuito de demonstrar como o discurso do neoliberalismo de austeridade vem se utilizando do critério de performance para legitimar-se como "modelo" econômico, social e político da pós-modernidade. A segunda seção demonstra que o princípio democrático tem cedido cada vez mais espaço ao princípio da eficiência, à medida em que o neoliberalismo expande seu modo de operar para todas as práticas sociais, tornando-se uma narrativa totalizante. Na terceira seção, procura-se compreender como o neoliberalismo de austeridade se utiliza do medo existencial para impor a austeridade fiscal como única opção de governança. A última seção abre a possiblidade de construção de outras narrativas como forma de frear o processo de totalização do neoliberalismo, ameaçador da democracia e do próprio ideal de justiça.

\section{O FIM DAS META-NARRATIVAS E A LEGITIMAÇÃO PELA PERFORMANCE}

A manipulação da conduta social por meio do medo existencial não é nova na história da humanidade: Lewis Mumford (1998), ao traçar as origens das cidades, associa o rei à figura que encarnava os poderes sagrados e podia, dessa maneira, controlar os acontecimentos naturais, evitando a fome e o perecimento. Durante grande parte da história antiga, as sociedades se mantiveram coesas por meio de 
narrativas segundo as quais a ira dos deuses poderia ser aplacada por meio de sacrifícios - de crianças, mulheres, cativos, animais e, em alguns casos, até do próprio rei. Tais narrativas serviam para conferir legitimidade às instituições e marcar positiva ou negativamente modelos de comportamento em relação aos padrões estabelecidos por cada sociedade.

$\mathrm{Na}$ modernidade, surgiram as meta-narrativas (ou grandes relatos), como "a dialética do espírito, a hermenêutica do sentido, a emancipação do sujeito racional ou trabalhador, o desenvolvimento da ciência", com a função de legitimar não mais os reis, mas a filosofia (LYOTARD, 1988, p. xv). As meta-narrativas filosóficas - de caráter especulativo, como o idealismo; ou emancipatório, como o marxismo - desembocaram, a partir do século XIX, em duas grandes espécies de discursos de representação da sociedade.

O primeiro deles enxerga a sociedade como um todo, um sistema cuja eficiência deve ser buscada na melhoria das próprias regras. Tal modelo constitui a base da teoria dos sistemas e do novo liberalismo que se instala a partir da década de 1960. As críticas endereçadas a esse modelo enfatizam que se trata de um modelo tecnocrático, em que

a verdadeira finalidade do sistema, aquilo que o faz programar-se a si mesmo como uma máquina inteligente, é a otimização da relação global entre os seus input e output, ou seja, o seu desempenho. Mesmo quando suas regras mudam e inovações se produzem, mesmo quando suas disfunções, como as greves, as crises, o desemprego ou as revoluções políticas podem fazer acreditar numa alternativa e levantar esperanças, não se trata senão de rearranjos internos e seu resultado só pode ser a melhoria da "vida" do sistema, sendo a entropia a única alternativa a este aperfeiçoamento das performances, isto é, o declínio (LYOTARD, 1988, p. 21).

O segundo modelo, de tradição marxista, vê a sociedade não como um todo orgânico, mas dividida pela luta de classes. O problema da narrativa marxista, segundo Lyotard (1988), é não ter sido capaz de preservar sua base teórica - o princípio da luta de classes - que acabou diluído nos modelos críticos desenvolvidos, posteriormente, pelas diversas escolas de inspiração marxista, como a Escola de Frankfurt. Assim, ao retirar o foco das lutas sociais, tal modelo corre o risco "de se reduzir a uma "utopia'” (LYOTARD, 1988, p.22-23).

A crise de legitimidade das meta-narrativas marca a passagem da modernidade para a pós-modernidade, conforme Lyotard (1988). O primeiro golpe no pensamento moderno é dado por Friedrich Nietzsche, ao anunciar o eterno retorno e a 
predominância do acaso sobre a ordem, colocando em dúvida a ideia do progresso, norteadora das meta-narrativas até então. O desenvolvimento acelerado das técnicas, a partir da segunda metade do século passado, desloca a importância dos fins para os meios de ação e abre caminho para a prevalência do critério de desempenho, de forma que "o importante agora não é afirmar a verdade, mas sim localizar o erro no sentido de aumentar a eficácia, ou melhor, a potência" (BARBOSA, 1985, p.xii). No campo da política, o fim da guerra fria deixa clara a "rejeição" ao modelo comunista e enfraquece a meta-narrativa marxista.

Os estudos sobre a linguagem e a própria proliferação de linguagens nãoverbais (linguagens das máquinas, linguagens dos códigos genéticos, linguagens de notação das lógicas, novas linguagens de notações musicais, gráficos de estruturas fonológicas etc.) colocam em xeque a unidade do discurso narrativo (BARBOSA, 1985). O golpe de misericórdia é dado pela teoria dos jogos de linguagem, quando se torna evidente que a filosofia, a ciência, a política, o direito, são legitimados por linguagens distintas umas das outras. Como enfatiza Lyotard (1988), "nada prova que, se um enunciado que descreve uma realidade é verdadeiro, o enunciado prescritivo, que terá necessariamente por efeito modificá-la, seja justo" (LYOTARD, 1988, p.72).

Com a proliferação de linguagens na sociedade pós-industrial, o cientista toma o lugar do sábio: passa a se comunicar em uma linguagem altamente especializada e a atuar em campos fragmentados do saber (LYOTARD, 1988). A substituição da reflexão - própria dos sábios - pelas técnicas exige a demonstração do conhecimento por meio de provas científicas. Estas, por sua vez, "obedecem a um princípio, o da otimização das performances: aumento do output (informações ou modificações obtidas), diminuição do in put (energia despendida) para obtê-las." (LYOTARD, 1988, p.80). Dessa forma, o critério de pertinência não é mais dado pela verdade, justiça ou beleza, mas pela eficiência: "um 'lance' técnico é 'bom' quando é bem-sucedido e/ou quando ele despende menos que um outro." (LYOTARD, 1988, p. 80).

As transformações trazidas pela tecnologia propiciam o desenvolvimento do neoliberalismo e suas facetas ${ }^{1}$. Até $\mathrm{o}$ início do século $\mathrm{XX}$, a economia clássica ou

\footnotetext{
${ }^{1}$ Como ensina o introdutor do Direito Econômico no Brasil, Washington Peluso Albino de Souza (2017), o neoliberalismo vem apresentando diversas facetas através dos tempos. A primeira delas, 0 neoliberalismo de regulamentação, iniciou-se no período pós-primeira Guerra Mundial e perdurou durante a guerra fria, quando o medo do socialismo real se fazia presente e as lutas pelos direitos sociais foram agudizadas. Tal faceta caracterizou-se pela intervenção do Estado empresário no domínio econômico via criação de empresas estatais de serviços públicos e atividades econômicas estratégicas (Direito Institucional Econômico) e produção de normas legais (Direito Regulamentar Econômico). Com o
} 
economia política - cuja origem remonta a Adam Smith -tinha como objeto de análise os mecanismos de produção, troca e consumo no interior de uma dada estrutura social (FOUCAULT, 2008). A partir do momento em que a economia incorpora o progresso tecnológico e passa a trabalhar de forma mais expressiva com a quantificação dos dados, torna-se cada vez mais um estudo de modelos mecânicos. As análises se voltam, agora, para os sistemas econômicos (máquinas destinadas à produção de mercadorias) e suas partes: os consumidores, as firmas e os governos (HEINEN, $2012)^{2}$.

Foucault (2008, p.306) relaciona essa "mutação epistemológica" com o início do neoliberalismo e com a alteração na própria concepção do homo oeconomicus ${ }^{3}$. Com a transformação da economia política em ciência econômica, essa disciplina deixa de se dedicar à análise da lógica histórica do processo de acumulação de riqueza e passa a se ocupar dos motivos que levam os indivíduos - reduzidos à condição de consumidor ou de trabalhador - a programarem estrategicamente suas atividades econômicas (FOUCAULT, 2008). Na economia clássica (fundamentação econômica do liberalismo), onde a geração de riqueza se dava pela mão invisível do mercado, o homo oeconomicus perseguia apenas o seu próprio interesse, cuja realização convergia, de forma não premeditada, com a realização do interesse dos outros. Já no neoclassicismo (fundamentação econômica do modelo neoliberal), o sujeito econômico não é mais um indivíduo autônomo, cuja maior virtude é a liberdade

fim do socialismo real e as transformações tecnológicas fragilizando os empregos formais, implantou-se, nas décadas de 1980 e 1990, o neoliberalismo de regulação, cujas caraterísticas foram a privatização do Estado empresário e a criação das agências de regulação (Direito Institucional Econômico) e de novos marcos regulatórios (Direito Regulamentar Econômico) em prol do setor privado. Finalmente, o neoliberalismo de austeridade - faceta analisada neste artigo e não identificada por Souza, surgiu após a crise financeira mundial de 2008 (NUNES, 2012; CLARK, CORRÊA, NASCIMENTO, 2017). Na atual faceta ocorre a dilatação das privatizações e criação das parcerias público-privadas (Direito Institucional Econômico) e de outros marcos reguladores (Direito Regulamentar Econômico) em prol dos lucros dos oligopólios privados, sobretudo do setor financeiro. O neoliberalismo de austeridade caracteriza-se, de um lado, pela retirada de direitos trabalhistas e pelo corte de investimentos públicos em setores sociais; e, de outro, pela redução da carga tributária das classes mais favorecidas, pagamento de juros elevados e concessão de vantagens econômicas às grandes empresas.

${ }^{2}$ A ciência econômica passa a se preocupar predominantemente com o estudo da utilidade, isto é, da "capacidade de bens e mercadorias satisfazerem as necessidades humanas." Seu objeto é o estudo das escolhas "ótimas" (alocação de recursos econômicos limitados para fins alternativos) e sua principal preocupação é compreender o funcionamento do sistema econômico e definir "as condições do equilíbrio geral da economia." (HEINEN, 2012, n.p.).

3 O termo homo oeconomicus é empregado em oposição ao homo politikos, utilizado por Aristóteles. Segundo o filósofo clássico, a natureza humana era constituída pela ação e pelo discurso (ARENDT, 2009). Para Adam Smith, ao contrário, "não é a ação, o discurso, o raciocínio moral, a deliberação ou a capacidade de associação que sinalizam nossa singularidade, mas sim a capacidade de efetuar transações mercantis; não é a autodeterminação política e coletiva que serve como base e indício de nossa existência civilizada, mas a produção de riqueza gerada pela divisão de trabalho (SMITH, 1976a)." (BROWN, 2015, p.272).

Revista de Direitos Fundamentais \& Democracia, Curitiba, v. 26, n. 1, p. 211-237, jan./abr. 2021. 
para empreender, mas um assalariado, cujo trabalho constitui a renda de um capital. $\mathrm{O}$ homo oeconomicus se torna, assim, apenas uma peça no funcionamento do sistema econômico (FOUCAULT, 2008).

O capital, por sua vez, não é mais uma máquina de produção. Do ponto de vista neoliberal, ele passa a ser a aptidão ou competência do empregado para realizar um serviço. Como afirma Foucault (2008), "do ponto de vista do trabalhador, o salário não é o preço de venda da sua força de trabalho, é uma renda", isto é, o rendimento do "conjunto de todos os fatores físicos e psicológicos que tomam uma pessoa capaz de ganhar este ou aquele salário" (FOUCAULT, 2008, p.308). Ao tornar-se o "empresário de si mesmo", o homo oeconomicus passa a ser, ao fim e ao cabo, "uma máquina que vai produzir fluxos de renda" (FOUCAULT, 2008, p.309) ${ }^{4}$.

Como a análise econômica passa a se ocupar das respostas comportamentais do indivíduo aos estímulos dados pelo meio ambiente, o comportamento humano incluindo sua aptidão e competência - pode ser mapeado, estimulado, controlado. O homo oeconimicus é aquele que "aceita a realidade ou que responde sistematicamente às modificações nas variáveis do meio", isto é, alguém "que vai responder sistematicamente a modificações sistemáticas que serão introduzidas artificialmente no meio". (FOUCAULT, 2008, p.369).

O papel do Estado, por sua vez, é controlar as práticas e comportamentos para que alcancem sua melhor performance. Segundo Heinen (2012, n.p.), "o neoliberalismo não é simplesmente a retirada do Estado" em prol do mercado, mas "uma política econômica que impõe um esquema de padrões de práticas e comportamentos pautadas pela concorrência" (HEINEN, 2012, n.p.). No campo das políticas públicas, os problemas não surgem como conflitos de interesses, mas como questões acerca da melhor escolha racional para se alcançar determinado fim: simulam-se situações de mercado e "exige-se daqueles que estão envolvidos que joguem como se fossem empresas, gerindo seus esforços para maximizar seus lucros" (HEINEN, 2012, n.p.)

Para se impor como um novo modelo de racionalidade, afirmam Dardot e Laval (2010), o neoliberalismo ${ }^{5}$ precisa suplantar a racionalidade burocrática, sustentada, nos últimos séculos, em sólidos pilares: a existência de uma fiç̧ão denominada interesse geral, que ocupa o centro do sistema burocrático-administrativo; a prevalência do

\footnotetext{
${ }^{4}$ Foucault (2008, p.309) utiliza o termo "fluxos de renda", ao invés de renda, porque, "a máquina constituída pela competência do trabalhador" tem uma duração de vida, um período de utilização, após o qual ela se torna obsoleta.

${ }^{5}$ Compreende-se que os autores se referem ao neoliberalismo de austeridade, conforme nota 1.
} 
direito público na organização da atuação do Estado; a disseminação de normas e formas organizacionais burocráticas nos mais diversos setores da vida; a negociação salarial entre classes sociais; e a distribuição de ganhos de produtividade. Esse é o motivo, segundo Dardot e Laval (2010), pelo qual o neoliberalismo procura constituir-se como uma forma "total" ou "transversal", isto é, como um modelo a ser aplicado a todos os setores de atividades. Tal mudança de racionalidade não se dá pelo confronto intelectual, mas pela difusão de um sistema de normas de ação (DARDOT; LAVAL, 2010) ${ }^{6}$.

Nesse sentido, Chauí (2018) afirma que o neoliberalismo7se converteu não só em um modelo econômico, mas sociopolítico, no qual a lógica da concorrência não está restrita às relações mercantis, mas atua também no plano das práticas sociais. De acordo com a filósofa, o neoliberalismo não é uma mutação histórica do capitalismo caracterizada pela substituição do capital produtivo pelo financeiro, mas uma mutação sociopolítica, que introduz uma nova forma de totalitarismo. O que caracteriza o totalitarismo, nesse caso, não é a figura de um líder autocrático, afirma Chauí (2018), mas a capacidade do neoliberalismo de transformar todas as instituições sociais em uma só instituição homogênea: a organização ${ }^{8}$. Em outras palavras: a capacidade de se tornar uma narrativa totalizante. A próxima seção se ocupará do neoliberalismo como modelo sociopolítico e da forma como ele opera em confronto com o modelo democrático.

\section{NEOLIBERALISMO E AUSTERIDADE FISCAL: 0 PRINCÍPIO DA}

\footnotetext{
${ }^{6}$ Dardot e Laval (2010) entendem que, mais do que uma ideologia ou política econômica, o que está em causa, no avanço do neoliberalismo, é a eficácia de um sistema de normas que opera, desde o início, por meio de prática e condutas. Esse sistema dá a todas as atividades - inclusive àquelas que não se destinam à produção de bens e serviços mercantis (fora, portanto, da esfera produtiva) - a forma de uma competição. Ocorre, assim, uma homogeneização dos modos de ser e de fazer sob aquilo que o jargão gerencial chama de "boas práticas".

7 Conforme nota 5, toma-se o termo "neoliberalismo" como "neoliberalismo de austeridade", em consonância com a nota 1.

${ }^{8}$ Para Chauí (2018), o neoliberalismo atua no campo das práticas sociais transformando as instituições em organizações. Instituições são, na definição da autora, ações sociais, isto é, práticas sociais que se legitimam pelo reconhecimento público de sua função e de suas atribuições próprias. É justamente essa diferenciação que permite às instituições se relacionarem umas com as outras e manterem a sua autonomia. Já as organizações são instrumentais, isto é, referem-se ao conjunto de meios para obtenção de um determinado objetivo e são, portanto, regidas pelo critério de eficiência na gestão, planejamento, previsão e controle das suas atividades. As organizações não se orientam pela ideia de reconhecimento público do seu papel na sociedade, mas pela eficácia de suas operações. Ao contrário das instituições, que acompanham as transformações da sociedade e, por isso, caracterizam-se por uma temporalidade aberta, as organizações têm um tempo efêmero, ou seja, elas se esvaem tão logo atingido seu objetivo (CHAUÍ, 2018).
} 


\title{
EFICIÊNCIA VERSUS O PRINCÍPIO DEMOCRÁTICO
}

Em 07/05/2012, Bresser Pereira escreveu um artigo na Folha de São Paulo intitulado Salvar o Euro ou Salvar a Europa? - em que indaga: "Se a política de austeridade se revelar uma ameaça séria à sobrevivência não apenas do euro, mas da própria União Europeia, por que não pensar seriamente na extinção do euro?" A pergunta evoca o que Bugaric (2013, p.4) vê como o dilema europeu:

\begin{abstract}
Hoje em dia, importantes economistas, cientistas políticos e juristas escrevem sobre um "trilema político" da União Europeia, que decorre da dificuldade, se não da impossibilidade estrutural, de combinar o mercado comum europeu com políticas sociais redistributivas no nível da União Europeia. Na sua forma mais extrema, o argumento sobre o viés neoliberal da ordem constitucional europeia postula que é estruturalmente impossível desenvolver uma versão social de economia de mercado na União Europeia (tradução livre). ${ }^{9}$
\end{abstract}

A situação em que se encontra a União Europeia não é surpreendente. Desde a formação do mercado comum europeu, temia-se que a centralização dos esforços da Europa em torno de um objetivo econômico acabasse por enfraquecer o controle do processo democrático. Para Nunes (2013, p.4), os críticos da unificação econômica da Europa perceberam que “o 'espírito do mercado comum' acabaria por privar os estados-membros dos meios e das competências indispensáveis para assegurar o controlo da economia pelo poder político democrático" (Nunes, p.6-7). A história acabou, na avaliação do autor, confirmando tal receio:

\begin{abstract}
Alguns anos mais tarde, logo a seguir à queda do Muro de Berlim (9.11.1989), Michel Rocard reconhecia, com grande frieza - seguindo, afinal, a lição de Mitterrand -, que "as regras do jogo do capitalismo internacional impedem qualquer política social audaciosa", aceitando que, "para fazer a Europa, é preciso assumir as regras deste jogo cruel" [...], vergando-se à lógica implacável da mercadização da economia e da vida [...] (NUNES, 2013, p.6-7)
\end{abstract}

Ao assinar o Tratado de Roma, que estabeleceu a constituição econômica do mercado comum europeu, as nações europeias adotaram, segundo Brunkhorst (2014), uma radical decisão: abdicar de uma constituição política. Em vez de fundar-se sobre a

\footnotetext{
${ }^{9}$ No original: "Nowadays, important economists, political scientists and lawyers write about a 'political trilemma' of the EU making it difficult if not structurally impossible to combine common economic market and redistributive social policies on the EU level. In its most extreme form, the argument about the neoliberal bias of European constitutional order postulates that it is structurally impossible to develop an EU version of social market economy" (BUGARIC, 2013, p. 4).
} 
afirmação de direitos políticos e sociais dos cidadãos europeus, a união da Europa se deu sobre bases econômicas, ou sobre o que o autor chama de "mindset gerencialista":

[...] a ordem concreta do lawand economics tornou-se a prerrogativa constitucional informal da Europa - o "curriculum secreto" europeu. [...] Um de seus efeitos mais cruciais foi a negação de qualquer transnacionalização da constituição política. A hegemonia do "currículo secreto" estimulou e reforçou a europeização de grandes empresas e federações de empresários, mas, ao mesmo tempo, limitou estritamente a ação de sindicatos e organizações de trabalhadores à esfera do Estado nacional. (BRUNKHORST, 2014, p.98-99)

De acordo com Brunkhorst (2014), o grande erro na implementação do euro sem a constituição de um governo supranacional foi estabelecer uma economia de "livre mercado" imune a qualquer forma de controle político e, ao mesmo tempo, manter os direitos sociais e trabalhistas vinculados à esfera de atuação dos Estados nacionais. O resultado do processo foi o crescimento das diferenças sociais entre as nações ricas, ao norte da Europa, e as pobres, ao sul. Com a crise do euro de 2010, o acirramento dessas diferenças se tornou ainda mais dramático, levando à hegemonia política das nações mais ricas, especialmente da Alemanha.

A solução encontrada para enfrentar a crise econômica do euro, por seu turno, foi a adoção de políticas que erigiram a austeridade e o equilíbrio orçamentário como princípios fundamentais da ordem constitucional da União Europeia (BUGARIC, 2013). Para Newman (2012), o mais surpreendente é que a política de austeridade, em última instância, acaba por revigorar as mesmas ideias que levaram à crise financeira e que Nunes (2012) denomina de "fascismo de mercado": a fé inabalável nos mercados oligopolizados e a sua frágil regulamentação (NUNES, 2012).

Kreuder-Sonnen (2016), em estudo recente sobre o déficit democrático das medidas econômicas adotadas pela Europa para superação da crise do euro, afirma que muitas dessas medidas, embora não possam ser chamadas de "ilegais", encontram-se na zona cinzenta de legalidade. São práticas extralegais, subterfúgios e experimentalismos, adotados originalmente como medidas excepcionais para socorro das nações endividadas, mas que correm o risco de se tornarem usuais ${ }^{10}$ (KREUDER-

10 Uma dessas medidas é o "pacote de socorro" da Grécia, em 2010, por meio do programa European Financial Stability Facility, que estabelece facilidades de crédito por meio de acordos intergovernamentais firmados sob a égide de leis privadas e internacionais. Segundo Kreuder-Sonnen (2016), o programa viola a cláusula de não-socorro financeiro entre os Estados-membros, prevista no artigo 125(1) do Treaty on the Functioning of the European Union. Para contornar a restrição da cláusula de não-socorro, o programa foi dotado de personalidade jurídica própria, de sorte que os débitos dos Estados deficitários não foram absorvidos diretamente - mas somente de forma indireta - pelos demais 
SONNEN, 2016). Como contrapartida para a assistência financeira prestada às nações em dificuldades financeiras, a Troika ${ }^{11}$ expediu uma série de exigências que atingiram direitos sociais e trabalhistas de milhões de cidadãos(tais como a garantia de salário mínimo, normas de proteção contra a demissão sem justa causa e acordos coletivos de negociação) e interferiram nas políticas públicas dos Estados socorridos, em áreas especialmente sensíveis (como seguridade social, saúde e educação), com imensos efeitos redistributivos de renda (KREUDER-SONNEN, 2016) ${ }^{12}$.

O descompasso entre as medidas de austeridade adotadas no âmbito da União Europeia e o quadro constitucional estabelecido pelos seus tratados de fundação tem levado alguns autores a recorrerem à figura do estado de exceção para caracterizar a recessão do governo democrático a partir da crise do euro (KREUDERSONNEN, 2016).Nesse caso, o estado de exceção não estaria configurado pela presença de um titular do poder que governa por decreto, mas pela existência de diversos atores que são autorizados a decidirem de modo autoritário, quando necessário ${ }^{13}$.Sob a justificativa de que as decisões não são políticas, mas técnicas, qualquer possibilidade de discussão acerca das escolhas é transferida aos tecnocratas:

\begin{abstract}
Nesse ponto, nós encontramos outra vez o mindsetgerencial: o bloco de órgãos executivos cada vez mais próximos, em concerto com o poder de elites políticoeconômicas, apoiado pelos onipresentes economistas chefes dos grandes bancos, pelos especialistas políticos e com inclinações jurídica, e por jornalistas cooptados (que são melhor pagos do que nunca e treinados sob o mesmo vocabulário econômico às custas de jornalistas freelancers que são pior pagos do que nunca), parece prevalecer sobre o poder popular kantiano. $\mathrm{O}$ debate público não é suprimido ou limitado, porém - mais eficientemente contornado pelo poder político e econômico como algo inútil ("nothelpfur'). (BRUNKHORST, 2014, p.104)
\end{abstract}

Estados-membros (KREUDER-SONNEN, 2016).

11 Troika é o órgão criado ad hoc pelo Fundo Monetário Internacional, Banco Central Europeu e Comissão Europeia para conduzir a negociação com nações que solicitam um pedido de resgate financeiro à União Europeia. Trata-se de uma equipe de consultores, analistas e economistas, ou seja, de tecnocratas destituídos de legitimidade representativa (KREUDER-SONNEN, 2016).

12 Outra medida que tem gerado questionamentos legais é o Procedimento de Desequilíbrio Excessivo PDE, mecanismo de controle de desequilíbrios macroeconômicos introduzido por legislação secundária. O PDE estabelece um regime amplamente discricionário de supervisão e gerenciamento econômico supranacional e permite, inclusive, sanções financeiras contra os Estados-membros que se recusarem a adotar as medidas corretivas "recomendadas" pela Comissão Europeia. Além disso, o Banco Central Europeu (BCE) tem sido criticado por extrapolar a sua competência ao introduzir programas de compra de títulos do governo de Estados-membros com problemas financeiros condicionados à adequação fiscal desses Estados. A atuação do Banco, nesse caso, não é técnica, mas estritamente política, o que traz à baila a legitimidade do BCE para representar os cidadãos europeus (KREUDER-SONNEN, 2016). ${ }^{13}$ Kuo (2014) compara a situação da Europa ao modelo constitucional norte-americano, em que os poderes emergenciais do Executivo são regulados pela legislação ordinária e acionados por meio de atividade discricionária administrativa. White (2015) prefere utilizar o termo "política de emergência" para se referir a ações distintas das práticas convencionais e racionalmente previstas como respostas a ameaças urgentes e excepcionais.

Revista de Direitos Fundamentais \& Democracia, Curitiba, v. 26, n. 1, p. 211-237, jan./abr. 2021. 
A totalização da narrativa neoliberal de austeridade ${ }^{14}$, sob a justificativa de que as decisões não são políticas, mas técnicas, elimina as diferenças e leva ao bloqueio dos conflitos (delas resultantes), impedindo, assim, a criação de direitos a partir do confronto entre os atores políticos (CHAUÍ, 2008). De outro lado, o indivíduo - antes sujeito de direitos e deveres sociais - transforma-se em um "empresário de si mesmo" (FOUCAULT, 2008, p.317), submetido às variações salariais do mercado de trabalho. Já que o Estado perde sua feição de instituição pública e passa a ser uma organização, todos os direitos, sejam eles econômicos, sociais ou políticos, são substituídos por serviços, negociados no mercado. Isso explica, segundo Chauí (2018), porque o governante agora se define como gestor e as políticas públicas se tornam questões de ordem técnico-administrativa, que devem ficar nas mãos de profissionais competentes, especialistas aptos a obterem os melhores resultados.

Para conseguir se sobrepor às demais narrativas, o neoliberalismo de austeridade precisa apagar o ideário dos direitos sociais, fortalecido gradativamente a despeito de alguns recuos - desde o Estado de Bem-Estar Social. A forma de conseguir suprimir tais direitos é eleger a austeridade como único caminho para a salvação. Dweck, Oliveira e Rossi (2018) analisam o discurso em prol da austeridade fiscal no Brasil e demonstram como as reações conservadoras - que já estavam presentes desde a promulgação da Constituição de 1988 - exacerbaram-se a partir de 2015:

\begin{abstract}
As teses ideológicas de que "o Estado brasileiro não cabe no PIB" ou "as demandas sociais da democracia não cabem no orçamento" passaram a ditar os rumos do debate econômico com repetidas afirmações de economistas e intelectuais a serviço do mercado financeiro, valendo-se de uma teoria econômica débil, do ponto de vista teórico e empírico. (DWECK; OLIVEIRA; ROSSI, 2018, p. 7)
\end{abstract}

Percebe-se, portanto, que o neoliberalismo de austeridade não resulta de uma operação de forças espontâneas do mercado. Ao contrário, sua extensão e reprodução precisam da ação do Estado, como enfatiza Jessop (2016). Em outras palavras, para substituir o discurso de garantia de direitos sociais pelo discurso da austeridade fiscal, o neoliberalismo, em sua faceta atual, precisaria enfrentar a resistência dos

\footnotetext{
${ }^{14}$ Como visto na seção anterior, Chauí (2018) entende que uma das características do neoliberalismo é o autoritarismo, revelado pela homogeneização de todas as instituições sob a forma de uma só instituição (a organização).
} 
beneficiários dos direitos sociais, o que levaria à solução do conflito pela via política e não tecnocrata. Contudo, o que se observa é uma surpreendente "resiliência" dos cidadãos diante das medidas de sacrifício impostas em prol do alardeado "saneamento das contas públicas". Como explicar a facilidade com que o discurso da austeridade vem sendo "vendido" à população como a única saída da crise? A próxima seção tentará lançar um pouco de luz sobre essa indagação.

\section{A PERCEPÇÃO DA CRISE E O MEDO EXISTENCIAL}

O discurso que apresenta a austeridade econômica como única solução para a crise econômica global não se sustenta em evidências econômicas, mas em argumentos frágeis e estudos controversos, afirmam Dweck, Oliveira e Rossi (2018). Um desses estudos é intitulado Crescimento em Tempos de Crise e assinado por Carmen Reinhart e Kenneth Rogoff, dois economistas da Universidade de Harvard. Considerado um marco na análise das crises econômicas, o trabalho demonstrou que uma dívida do governo superior a $90 \%$ do PIB impede qualquer chance de crescimento econômico. Os argumentos dos autores abalaram o keynesianismo e foram utilizados para justificar a adoção de medidas de austeridade fiscal em todo o mundo:

\footnotetext{
O "paper"de Reinhart e Rogoff possivelmente teve influência mais imediata no debate público do que qualquer outro estudo na história da economia. A afirmação dos $90 \%$ foi citada como o argumento decisivo a favor da austeridade por figuras que iam de Paul Ryan, 0 ex-candidato à Vice-Presidência dos Estados Unidos, que hoje preside a Comissão do Orçamento da Câmara dos Representantes, a OlliRehn, a principal autoridade econômica da Comissão Europeia, ao conselho editorial do jornal "The Washington Post". (KRUGMAN, 2013, n.p.)
}

O trecho acima foi traduzido de um artigo escrito pelo economista ganhador do Nobel em 2018, Paul Krugman, e publicado no New York Review of Books, logo após a descoberta de que as evidências científicas apresentadas por Reinhart e Rogoss para demonstrar sua argumentação continham erro de codificação em uma planilha e vários erros na análise dos dados. Krugman (2013) lembra que o discurso de austeridade também foi reforçado pelo trabalho de Alberto Alesina, da Universidade de Harvard, que junto com Sílvia Argana, utilizou dados históricos para afirmar que "grandes cortes de gastos em países avançados sempre foram, em média, seguidos de expansão, e 
não de contração" (KRUGMAN, 2013, n.p.) ${ }^{15}$. Krugman (2013) argumenta em sentido contrário: dados mais recentes, obtidos a partir da adoção das medidas de austeridade pelas nações deficitárias da União Europeia, demonstram que o resultado dessa política vem sendo desastroso ${ }^{16}$ :

[...] os países que foram forçados a adotar medidas de austeridade severas experimentaram recessões bastante severas, que foram mais ou menos proporcionais ao grau de austeridade. Foram feitas algumas tentativas para explicar esses resultados, especialmente na Comissão Europeia. Mas o FMI analisou a fundo os dados e não só concluiu que a austeridade teve grandes efeitos econômicos adversos, como também emitiu o que pode ser classificado como um "mea culpa", por ter subestimado esses efeitos adversos [...] (KRUGMAN, 2013, n.p.)

Blyth (2017) demonstra que o discurso da austeridade não só tem efeitos nocivos nas economias, como afeta a própria coesão social, além de causar traumas e sofrimentos. Reportagem publicada na BBC News, em 18 de julho de 2015, fez um balanço da situação da Grécia em meio à política de recessão. De acordo com a reportagem, entre 2008 e 2013 os gregos ficaram em média 40\% mais pobres em razão do fechamento de postos de trabalho, cortes salariais e suspensão de benefícios sociais. Um dos setores que sofreu maior impacto foi o de saúde pública, especialmente o setor de saúde mental 17 (RODGERS; STYLIANOU, 2015). A reportagem relata um aumento impressionante de 35\% na taxa de suicídios na Grécia entre 2010 e 2012. Além disso, a crise expôs a precariedade dos serviços de seguridade social: $20 \%$ da população grega passava por grave privação material em

\footnotetext{
${ }^{15}$ Alberto Alesina e Sílvia Argana sustentaram que a austeridade fiscal gera confiança no setor privado, o que compensa os efeitos gerados pela retração de gastos do governo, tese utilizada pelo Conselho Europeu, em 2010, para justificar as medidas de austeridade encaminhadas pela Comissão Europeia e pelo Banco Central Europeu. (KRUGMAN, 2013)

16 Conforme publicação da revista Dinheiro Vivo, em 19/08/2018: "Tal como a figura mitológica de Prometeus, a economia grega parece amarrada a uma pedra desde a chegada da troika em 2010. 0 ritmo de crescimento é lento e ainda não conseguiu recuperar para os níveis de há oito anos. O Produto Interno Bruto (PIB) está 21\% abaixo de 2010" (PINTO, 2018). Portugal, embora tenha conseguido atingir o nível de produção pré-crise, teve a expectativa de crescimento de sua economia, que era de $2,3 \%$ em outubro de 2018, revista para $2,1 \%$ do PIB, ou seja, $0,7 \%$ a menos do que no ano anterior (REVISTA OBSERVADOR, 2019). O crescimento previsto para os próximos anos também foi revisto para baixo, conforme reportagem da revista Público, publicada em 19/12/2018(ANIBAL, 2018). Na Irlanda, operouse o chamado "milagre econômico", que levou à aparente recuperação da economia em três anos. Contudo, em 2017, as próprias autoridades estatísticas irlandesas propuseram a substituição do PIB pelo Índice de Rendimento Nacional Bruto para medição do crescimento econômico do país, uma vez que a situação de crescimento apresentada pelo aumento do PIB não se refletia no aumento da renda per capta dos irlandeses, segundo noticiado pela revista Público, em 07/08/2017 (ANIBAL, 2017).

17 Os serviços de saúde mental sem fins lucrativos foram obrigados a reduzir suas operações e os projetos de atendimento psiquiátrico a crianças foram deixados de lado. Os fundos para saúde mental caíram cerca de $20 \%$ entre 2010 e 2011 e mais 55\% no ano seguinte (RODGERS; STYLIANOU, 2015).
}

Revista de Direitos Fundamentais \& Democracia, Curitiba, v. 26, n. 1, p. 211-237, jan./abr. 2021. 
2015, índice que equivale a quase o dobro daquele verificado em 2008. Em 2014, quase quatro milhões de pessoas (mais de $1 / 3$ da população) na Grécia estava em situação de risco de pobreza ou exclusão social (RODGERS; STYLIANOU, 2015).

Ao analisar os efeitos da política de austeridade fiscal adotada pelo Brasil desde 2015, Dweck, Oliveira e Rossi (2008) afirmam que, embora o Brasil tenha reduzido a desigualdade social nos anos anteriores, os cortes em gastos públicos realizados recentemente já tiveram como efeitos diretos: aumento da mortalidade infantil (após uma queda constante que durou 26 anos), precarização dos serviços de saúde, aumento da extrema pobreza, diminuição no número de empregos com carteira assinada, diminuição do padrão de consumo das famílias com menor renda, aumento da população de rua e intensificação da sensação de insegurança nas cidades. Ainda que se argumente que tais efeitos decorrem da própria crise econômica, os autores enfatizam que a austeridade tem um efeito perverso na concentração de renda, já que ela atua de forma seletiva, atingindo de forma mais intensa os grupos mais desfavorecidos econômica e socialmente, como os negros e as mulheres. Nunes (2012) também aponta os mesmos efeitos negativos, dentre outros, do neoliberalismo de austeridade comandado pelos oligopólios do setor financeiro internacional.

O panorama acima revela que, longe de existir consenso sobre os efeitos positivos das políticas de austeridade, vários estudos conduzidos por economistas concluem que ela não é a medida adequada para superação de crises econômicas como a que teve início em 2008. Por que motivo, então, a austeridade fiscal vem sendo apresentada como a "única solução" para a sobrevivência econômica das nações? Por que os cidadãos estão abrindo mão, "sem resistência", dos direitos sociais conquistados ao longo de décadas? Não se pretende, dado ao escopo do trabalho, responder a todas essas questões. Por outro lado, é interessante refletir acerca do modo como o neoliberalismo reforça o discurso da austeridade de forma a legitimar-se como sistema econômico e sociopolítico hegemônico.

A percepção da crise econômica é variável de um indivíduo para outro: uma mesma crise econômica pode ser percebida de forma mais ou menos intensa; pode ser partilhada de forma ampla pelos indivíduos ou ficar restrita a certos segmentos da sociedade; e pode ser considerada de curta ou longa duração (KREUDER-SONNEN, 2016). Crises percebidas de forma especialmente intensa podem ser utilizadas para justificar a adoção de medidas de exceção e dotar os tecnocratas de autoridade extraordinária. A forma como a crise econômica é percebida está diretamente ligada ao 
medo existencial, isto é, ao pavor de acontecimentos que ameaçam a capacidade de subsistência dos indivíduos, dentre eles a falta de alimentos e de cuidados de saúde e a exposição à violência (KREUDER-SONNEN, 2016).

Antes do advento do Estado Moderno, o medo existencial era administrado no seio das comunidades, por meio de relações de parentesco e vizinhança, e, à medida que as corporações começaram a oferecer proteção em troca do dever individual de solidariedade, por laços comunitários. A função de "administrar o medo" do perecimento passou às mãos do Estado quando as revoluções políticas privaram os indivíduos da rede de proteção social que lhes era naturalmente ofertada no passado, à mesma época em que o iluminismo retirou a responsabilidade pelos seus destinos das mãos de Deus e colocou-a em suas próprias mãos (BAUMAN, 2007, p.65).

Bauman (2007) enfatiza que, ao contrário do que se pensa, não é a distribuição de renda que está na base do Estado de Bem-Estar Social, mas a proteção contra o infortúnio individual. Como essa proteção não era oferecida a todos indiscriminadamente, mas apenas aos que detinham algum capital econômico, cultural ou social, o Estado passou a organizar uma estrutura de proteção social fundada em instituições previdenciárias, regras trabalhistas e serviços públicos.

Essa rede de solidariedade, complementada por associações, sindicatos e grupos sociais nos quais os indivíduos compartilhavam interesses e rotinas comuns, esvaiu-se no processo de globalização (BAUMAN, 2007). A garantia de proteção contra as ameaças existenciais deixou de ser ofertada pelos Estados nacionais e ficou a cargo dos próprios indivíduos - e eventualmente do mercado. Com a retração do Estado na prestação de serviços públicos, sua autoridade passou a ser legitimada por meio da proteção pessoal dos indivíduos contra as ameaças de "um pedófilo à solta, de um serial killer, de um mendigo atrevido, de um assaltante, de um molestador, envenenador, terrorista" ou seja, dos "meliantes" (BAUMAN, 2007, p.21).

Além do medo do outro, existe um medo maior que aflige o indivíduo na pósmodernidade: o medo do fracasso. Conforme Chauí (2018), o afrouxamento dos vínculos sociais faz com que o indivíduo não se perceba mais como pertencente a uma classe, um grupo, um conjunto ou qualquer outra forma de associação baseada na solidariedade. Ele também não é mais portador de direitos, mas consumidor de serviços. À medida em que se torna o único responsável pelo seu próprio destino, segundo a lógica da meritocracia (característica da hierarquia organizacional), aquele que não consegue se mostrar competitivo é excluído do sistema (CHAUÍ, 2018). 
Bauman (2007) vê ressurgir, no neoliberalismo (reforçado na faceta de austeridade), a figura do marginalizado, que, no declínio da era medieval era o excedente populacional excluído das benesses do desenvolvimento industrial e deixado sem proteção pela falência das instituições medievais de proteção. Na era da globalização, esses indivíduos são as pessoas que não pertencem a qualquer divisão de classes, alijados das "funções reconhecidas, aprovadas, úteis e indispensáveis que os membros 'normais' da sociedade executam" (BAUMAN, 2007, p.76). O marginalizado não está desempregado (o que, por contraposição, exigiria que ele pudesse estar em outra condição: a de empregado): ele detém um estado, que é o de não ter emprego, o que "implica ser descartável, talvez até ser descartado de uma vez por todas" (BAUMAN, 2007, p.75).

Nesse ponto, parece claro que, seo homo oeconomicus do neoliberalismo não é um parceiro de produção ou de troca, como no modelo liberal, mas uma máquina que produz um fluxo de renda (FOUCAULT, 2008), seu sucesso depende não apenas da sua própria competência, mas do seu grau de obsolescência. Em um ambiente competitivo, no qual o critério de eficiência é hipervalorizado, preservar a própria "utilidade" torna-se uma atividade sujeita a grande tensão psicológica. Tal tensão - que leva ao medo e insegurança - é manipulada pelo neoliberalismo para aumentar a performance dos indivíduos e, consequentemente, do próprio sistema, como percebem Dardot e Laval (2010, p. 42):

\begin{abstract}
Deve-se acrescentar também que, como o fator de competitividade mais importante hoje é o "capital humano", a formação do indivíduo, seu "desenvolvimento pessoal" dentro e fora da empresa, sua subjetividade no trabalho e na vida privada, devem também ser remodelados de acordo com o princípio da concorrência. É esse o ponto no qual o discurso neoliberal mais insiste, embora na prática tenha se mostrado difícil: prover a economia de indivíduos melhor adaptados à guerra comercial generalizada, ou seja, dos melhores realizadores. O treinamento desses indivíduos e a manutenção "ao longo da vida" de sua capacidade de enfrentar a concorrência encontram um veículo privilegiado na competição entre os trabalhadores. As virtudes de uma gestão com enfoque psicológico e contábil mostrou sua eficácia nessa área, não sem causar uma devastação humana cuja extensão estamos descobrindo (tradução livre) ${ }^{18}$.
\end{abstract}

\footnotetext{
${ }^{18}$ No original:"Il faut encore ajouter que, dès lors que le facteur de compétitivité le plus important est aujourd'hui le "capital humain", la formation de l'individu, son "développement personnel" dans et hors l'entreprise, sa subjectivité au travail comme dans la vie privée, doivent également être remodelés selon le principe de la concurrence. C'est même d'ailleurs le point sur lequel les discours néolibéraux insistent le plus, bien que la mise en pratique s'avère difficile: fournir à l'économie les individus les mieux adaptés à la guerre commerciale généralisée, c'est-à-dire les plus performants. La formation de ces individus et l'entretien "tout au long de la vie" de leur capacité à affronter la compétition trouvent un véhicule privilégié dans la mise en concurrence des travailleurs entre eux. Les vertus d'un management
}

Revista de Direitos Fundamentais \& Democracia, Curitiba, v. 26, n. 1, p. 211-237, jan./abr. 2021. 
A manipulação da sensação de medo e de culpa pelo fracasso é uma das características do discurso neoliberal de austeridade. Para Chauí (2018), a ideia de que o indivíduo é destinado a competir em todas as organizações da sociedade - e não de interagir politicamente por meio de instituições sociais - é explorada para gerar culpa por parte daqueles que não conseguem vencer a competição. Por outro lado, ao atribuir seus defeitos à incapacidade dos indivíduos de se manterem úteis e competitivos, o sistema capitalista se reajusta e consegue melhorar sua performance.

Da mesma forma que as falhas do sistema são atribuídas aos indivíduos, as crises econômicas são explicadas pela insistência dos Estados em gastarem mais do que podem, jamais por outros motivos econômicos, sociais ou tecnológicos. Para Krugman (2013), um dos motivos pelos quais o discurso da austeridade, apesar de todas as evidências contrárias, "obteve aceitação" por parte da opinião pública, é o fato de que as pessoas tendem a buscar representações morais para explicar problemas que "simplesmente acontecem". Sob a perspectiva da macroeconomia, esse comportamento reflete-se na crença infundada de que recessões econômicas são consequências de excessos praticados anteriormente e, portanto, exigiriam "um processo inevitável de limpeza" (KRUGMAN, 2013, n.p.) ${ }^{19}$.

Daí porque Wilkinson (2013, p.528) utiliza o termo "chicote da necessidade" (“whipofnecessity") para explicar porque a integração da União Europeia se faz hoje não mais pela via da lei e da política, mas pela via do discurso de salvação. Os europeus passaram a se contentar com uma democracia parcial, em que os indivíduos são colocados uns contra os outros diante do aviso de que é seguir a correnteza ou afundar. Assim, normas legais e acordos políticos são suspensos para garantir uma suposta preservação da estabilidade financeira e do livre mercado (WILKINSON, 2013), enquanto a coesão social e a segurança são deixadas de lado.Para Wilkinson (2013), as práticas do liberalismo autoritário ${ }^{20}$ estariam escondendo o conflito entre democracia e capitalismo ao enunciar um poderoso lema, segundo o qual não há alternativa ("thereis no alternative"). A próxima seção se debruçará sobre esse lema.

à tendance psychologique et comptable ont montré en ce domaine leur efficacité, non sans entraîner des ravages humains don't nous découvrons l'ampleur" (DARDOT; LAVAL, 2010, p. 42).

${ }^{19} \mathrm{O}$ autor assinala que, "em contraste, a economia keynesiana se baseia fundamentalmente na premissa de que a macroeconomia não é uma representação moral - as depressões são essencialmente uma disfunção técnica" (KRUGMAN, 2013, n.p.).

20 Wilkinson $(2013$, p. 528) parte de uma perspectiva crítica que realça os conflitos existentes entre o capitalismo e a democracia e utiliza o termo "liberalismo autoritário" para se referir ao modelo políticoeconômico da União Europeia. 


\section{OUTRA NARRATIVA É POSSÍVEL?}

Até o momento, "a frágil balança de poder entre democracia e capitalismo pendeu dramaticamente em favor do capitalismo", nas palavras de Brunkhorst (2014, p.105). Ao contrário do que ocorreu durante o New Deal, nos Estados Unidos - quando a classe de trabalhadores organizados em sindicatos conseguiu impulsionar a proteção aos direitos sociais -, as nações têm se mostrado extremamente sensíveis ao poder do capital, especialmente no nível transnacional. Brunkhorst (2014) acredita que as chances de garantir a preservação dos direitos sociais e econômicos estão na "reinvenção da luta de classes democrática no nível transnacional" (BRUNKHORST, 2014, p.107). Contudo, os atores políticos que poderiam promover esse confronto político estão "particularmente" inertes.

Depois de quase dez anos do início da crise do euro, medidas que apareciam como alternativas excepcionais passaram a ser aceitas como uma mudança natural na condução dos assuntos econômicos pela União Europeia (KREUDER-SONNEN, 2016). O fortalecimento das ideias neoliberais, por sua vez, dificulta a construção de um quadro social democrático alternativo, como já diagnosticado por Newman (2012) e Santos (2016). Brunkhorst (2014) explica que

\footnotetext{
O problema não reside apenas no mindset gerencialista, mas em sua hegemonia e na redução da política à tecnocracia, que hoje permite a elites econômicas e políticas ignorar e manipular a opinião pública e o direito público legitimado democraticamente nos dois níveis: tanto no nível europeu como nos respectivos níveis nacionais. Ao mesmo tempo em que isso avança do ponto de vista jurídico, o poder público do povo e de seus órgãos representativos se torna, mais e mais, desprovido de poder real e é substituído por redes cinzentas de governo informal - por vezes chamadas de "boa governança" (goodgovernance) em vez de governo democrático, "accountalibity administrativa" em vez de responsabilidade parlamentar, "democracia deliberativa" em vez de "tomada igualitária de decisões" (BRUNKHORST, 2014, p.98).
}

Nesse passo, é importante voltar a uma indagação feita por Lyotard (1988) a respeito da legitimação do saber científico: o que pode evitar que os jogos de linguagem da ciência venham a se legitimar por meio de códigos diferentes do seu código específico (verdadeiro/falso)? Se considerarmos o direito e a política, a questão seria: como evitar que os jogos de linguagem se legitimem por códigos que não o justo/injusto e o legítimo/ilegítimo, respectivamente? De fato, como visto na primeira 
seção, nos jogos de linguagem da tecnologia o código eficiente/ineficiente diretamente ligado ao poder econômico privado (oligopólios) - é utilizado para aumentar a performance do sistema, legitimando, assim, as escolhas. Nas ciências, na administração da justiça e na política prevalecem - ou deveriam prevalecer - os códigos binários verdadeiro/falso, justo/injusto e legítimo/ilegítimo, respectivamente. Contudo, também é verdade que a introdução do código binário eficiente/ineficiente em outros jogos de linguagem acaba por legitimá-los de fato, por meio do que Lyotard (1988, p.84) chama de domínio da realidade:

[...] sendo a "realidade" que fornece as provas para a argumentação científica e os resultados para as prescrições e as promessas de ordem jurídica, ética e política, pode-se vir a ser senhor de ambas tornando-se senhor da "realidade", o que as técnicas permitem. Reforçando-as, "reforça-se" a realidade, consequentemente, as chances de ser justo e de ter razão. E, reciprocamente, reforça-se tanto as técnicas de que se pode dispor do saber científico e da autoridade decisória (LYOTARD, 1998, p.84).

Tal legitimação, chamada pelo autor de "legitimação pelo poder" (LYOTARD, 1998, p.84), é utilizada pelos tecnocratas, ao comandarem os in-puts e out-puts na sociedade como um todo. O controle do contexto tecnológico-informacional aumenta a eficácia de um enunciado, seja ele denotativo ou prescritivo. Em outras palavras, quanto mais se tem a capacidade de produzir, memorizar, acessar e operacionalizar as informações, maior é o poder de legitimação que se dispõe. Evidentemente, quanto mais complexas as informações e mais sofisticados os meios de prova, maior é o poder de quem os detém (LYOTARD, 1988).

É dessa forma que se legitima a narrativa do neoliberalismo de austeridade. De acordo com tal narrativa, a sociedade não tem capacidade de identificar suas necessidades, porque lhe falta a competência ${ }^{21}$. Essa competência é retratada como própria da tecnocracia - que detém o conhecimento especializado das novas tecnologias e acesso a um conjunto enorme de informações. À medida que a performance - critério de legitimação das práticas tecnocráticas - é estendida a todas as áreas do saber, a narrativa neoliberal da faceta de austeridade se torna totalizante. Seria tal cenário, então, inevitável?

Com base na teoria dos jogos de linguagem, desenvolvida por Ludwig Wittgenstein, Lyotard (1988) faz três observações: (i) as regras do jogo não estão

\footnotetext{
${ }^{21}$ Ao mesmo tempo, os tecnocratas tendem a considerar a sociedade como uma unidade, e não como o locus de diversos comportamentos, visões de mundo e maneiras de viver.
} 
legitimadas por si próprias, elas são objeto de acordo (explicito ou não) entre os participantes; (ii) se não houver regras, não há jogo (assim como uma modificação qualquer em uma regra altera a natureza do jogo e um enunciado que não obedeça às regras não faz parte do jogo); e (iii) todo enunciado é um lance feito no jogo. Além disso, Lyotard (1988) enfatiza que existe uma agonística implícita ao discurso, isto é, os jogos de linguagem colocam seus participantes em uma disputa constante.

Para evitar que a narrativa neoliberal de austeridade domine todos os setores da vida social, é preciso - na linguagem dos jogos - que os participantes questionem as próprias regras do jogo. Isso é possível porque, como visto, as regras não são legitimadas por si mesmas, elas dependem de acordos entre os participantes. $O$ questionamento depende da percepção, por parte dos participantes, de que os critérios de legitimação das diferentes práticas sociais são incomensuráveis, ou seja, de que diferentes tipos de enunciados são produzidos por diferentes jogos de linguagem. A constatação de que, ao lado do código eficiente/ineficiente, existem outros códigos legitimando as práticas sociais nas diferentes áreas de atuação do indivíduo (no direito, na política, nas ciências) leva ao surgimento de novos lances nos jogos ${ }^{22}$, não controláveis pelo critério da performance.

O que Lyotard sugere, na verdade, é a produção de instabilidades capazes de perturbar o sistema ${ }^{23}$. Nesse ponto, é importante distinguir o que ele considera de inovações no sistema - destinadas a melhorar sua performance - de perturbações cujo efeito é a revisão das regras do jogo:

É preciso supor um poder que desestabilize as capacidades de explicar e que se manifeste pela regulamentação de novas normas de inteligência ou, se se prefere, pela proposição de novas regras para o jogo de linguagem científico, que irão circunscrever um novo campo de pesquisa. (LYOTARD, 1988, p.112).

Do ponto de vista das práticas sociais, o poder de desestabilizar uma narrativa

\footnotetext{
${ }^{22}$ A grande vantagem da pós-modernidade, segundo Lyotard (1988), é que embora tenha substituído as meta-narrativas por uma narrativa baseada em critérios de performance, ela também permite o aparecimento - de forma concomitante - de uma multiplicidade de pequenas narrativas. São essas pequenas narrativas, com seus inúmeros jogos de linguagem, que permitem introduzir novos lances nos jogos de linguagem e, eventualmente, rever as suas próprias regras de racionalidade.

${ }^{23}$ Do ponto de vista científico, podemos compreender os lances de perturbação do sistema a partir do estudo de paradigmas proposto por Kuhn (1998). De acordo comesse autor, os cientistas, ao realizarem suas pesquisas, excepcionam, como "anomalias", algumas constatações que não se enquadram no paradigma vigente. Contudo, conforme as pesquisas vão progredindo, as "anomalias" vão se tornando mais frequentes, até que os membros da comunidade científica não podem mais se esquivar da sua existência. Inicia-se, então, a fase de "investigações extraordinárias" (fora do âmbito da pesquisa normal), que acaba por conduzir a um novo paradigma (KUHN, 1998, p. 24-25).
}

Revista de Direitos Fundamentais \& Democracia, Curitiba, v. 26, n. 1, p. 211-237, jan./abr. 2021. 
totalizante provem de outras narrativas produzidas a partir de diferentes jogos de linguagem ${ }^{24}$. Existe uma diferença marcante entre a linguagem das ciências e a linguagem das práticas sociais: enquanto o saber científico opera com apenas um jogo de linguagem (o denotativo); as práticas sociais produzem, a partir de diferentes jogos de linguagem, um conjunto de enunciados heteromorfos: "denotativos, prescritivos, performativos, técnicos, avaliativos etc." (LYOTARD, 1988, p.117). Isso impede a construção de um "consenso revisável” (LYOTARD, 1988, p.117) ou paradigma, na terminologia utilizada por Kuhn (1998), e leva à coexistência de várias narrativas ou relatos concomitantes ${ }^{25}$.

Dweck, Oliveira e Rossi (2018, p.13) afirmam que, "felizmente, há alternativas ao caminho da austeridade econômica e essas passam pelo fortalecimento da democracia e pela construção de um modelo de desenvolvimento que busque o crescimento com transformação social"26. Para Blyth (2017), a história demonstra que a saída da crise econômica é distribuição de renda e combate enérgico à desigualdade, com ampliação dos direitos dos trabalhadores. A pergunta a se fazer, a esta altura, não é se Dweck, Oliveira e Rossi (2018) ou Blyth (2017) estão certos ou não. Mas por que motivo esse discurso não é considerado no debate público? Por que teorias que não foram sequer legitimadas pelo critério verdadeiro/falso foram usadas até o momento para justificar políticas fiscais de austeridade que, ao fim e ao cabo, se mostraram inadequadas, para não utilizar o termo "desastrosas", empregado por

\footnotetext{
${ }^{24}$ Lyotard (1988) alerta para o fato de que uma das maneiras pelas quais o sistema pode se proteger contra lances que possam perturbar sua eficácia é por meio da exclusão dos participantes do jogo. Isso se dá pelo que o autor denomina de "terror", isto é, a eliminação ou ameaça de eliminação de participante por meio do seguinte enunciado: "Adaptai vossas aspirações aos nossos fins, senão ... ". A utilização do terror se dá fora do jogo da linguagem, uma vez que subverte as suas regras, e tem como efeito a imobilização do oponente. Nessa situação, elimina-se não só o parceiro, mas o próprio vínculo social (LYOTARD, 1988, p. 115-116).

${ }^{25}$ Essa constatação tem, para Lyotard (1988) duas consequências: a primeira é o reconhecimento de que a justiça não pode ser obtida pelo consenso, mas pela disputa entre múltiplas narrativas elaboradas em uma multiplicidade de jogos de linguagem. A segunda consequência é o princípio segundo o qual qualquer consenso sobre as regras dos jogos de linguagem deve ser local e temporário, ou seja, vale para os participantes do jogo atual e está sujeito à eventual anulação. Ao aplicar essas duas regras na busca de um critério de justiça, renuncia-se, automaticamente, à narrativa totalizante do neoliberalismo de austeridade.

${ }^{26}$ Dweck, Oliveira e Rossi (2018) propõem como alternativa para vencer a crise econômica a ampliação do impacto fiscal por meio de uma reforma tributária que aumente a tributação com efeitos redistributivos de renda e a mudança do perfil de gastos públicos, com ampliação da oferta de bens e serviços públicos pela transferência de renda. Os autores entendem que a distribuição de renda e o investimento social são importantes impulsionadores do desenvolvimento econômico. A primeira, porque contribui para consolidar um mercado interno dinâmico que pode aumentar a escala de produção e proporcionar ganhos de produtividade para as empresas domésticas. O segundo, porque tem efeitos dinâmicos de curto prazo (multiplicadores de gastos e geração de empregos) e de longo prazo (melhoria da qualidade de vida dos trabalhadores e aumento da produtividade da economia).
}

Revista de Direitos Fundamentais \& Democracia, Curitiba, v. 26, n. 1, p. 211-237, jan./abr. 2021. 
Krugman (2013)? A procura de respostas para tais questionamentos pode levar a novos lances no jogo, movidos pelo dissenso, e, quem sabe, alterar suas regras.

\section{CONSIDERAÇÕES FINAIS}

O artigo buscou compreender por que motivo o neoliberalismo de austeridade, a despeito da fragilidade de seus argumentos científicos, vem conseguindo se impor na pós-modernidade não só como um "modelo econômico", mas sociopolítico. Por meio de uma narrativa segundo a qual a austeridade fiscal é a única solução para a superação da crise econômica global de 2008, grande parte das nações tem sacrificado direitos sociais e trabalhistas e o próprio princípio democrático, como demonstra a experiência da União Europeia. Apesar disso, o discurso neoliberal de austeridade fiscal tem conseguido "eliminar o dissenso" e legitimar-se politicamente.

A partir dos estudos de Jean-François Lyotard, demonstrou-se que a narrativa neoliberal de austeridade utiliza como critério de legitimidade a performance, medida pelo aumento do resultado (out put) com diminuição da energia despendida (in put). $\mathrm{Na}$ tentativa de se firmar como narrativa totalizante, o neoliberalismo de austeridade vem se impondo sobre as demais narrativas por meio da substituição dos códigos de legitimação próprios de cada uma das áreas de conhecimento (verdadeiro/falso, nas ciências; justo/injusto, no direito; legítimo/ilegítimo, na política, etc.) pelo código eficiente/ineficiente, específico da linguagem tecnológica.

Ao preponderar sobre as demais narrativas, o neoliberalismo (na sua faceta atual) elimina as diferenças e torna as instituições homogêneas, em um movimento que contrapõe o princípio da eficiência ao princípio democrático. $\mathrm{O}$ discurso de austeridade é apresentado - sob essa perspectiva - como uma tentativa de autocorreção do sistema capitalista diante de falhas operacionais: os defeitos de funcionamento, como desemprego, greves, corte de gastos (in put) são tratados como oportunidades de corrigir e melhorar o seu desempenho (out put). Nesse processo são eliminadas as diferenças, os conflitos e a possibilidade de criação de direitos.

"A pouca resistência" enfrentada pelos governos para impor o discurso neoliberal de austeridade é explicada, a partir do pensamento de Michel Foucault e ZigmuntBauman, pela eliminação do dissenso por meio da manipulação do medo e da culpa dos indivíduos. Tais sentimentos são exacerbados à medida em que cada indivíduo se torna um "empresário de si mesmo" e precisa manter-se competitivo para 
evitar a exclusão social.

Finalmente, a partir das observações feitas por Lyotard acerca da teoria dos jogos, de Ludwig Wittgenstein, demonstrou-se que existe a possibilidade de se substituírem lances inovativos - que melhoram a performance do sistema - por lances perturbadores, capazes de promover o dissenso e, assim, alterar as regras do jogo. Tal dissenso se manifesta por meio de pequenas narrativas que, ao invés de aceitarem a utilização generalizada do código binário eficiente/ineficiente, reconhecem a existência de outros códigos preponderantes nas diferentes áreas do saber.

\section{REFERÊNCIAS}

ANIBAL, Sérgio. Economia mundial abranda e Portugal já está a sentir o impacto. Revista Público, edição digital, 19 dez. 2018. Disponível em:<https://www.publico.pt/2018/12/19/economia/noticia/economia-mundial-abrandaportugal-ja-sentir-impacto-1855186>. Acessado em 25 jan. 2019.

ANIBAL, Sérgio. Num só dia, o milagre irlandês passou a ser $30 \%$ menos impressionante. Revista Público, edição digital, 07 ago. 2017. Disponível em:<https://www.publico.pt/2017/08/07/economia/noticia/num-so-dia-o-milagreirlandes-passou-a-ser-30-menos-impressionante-1781509>. Acessado em 25 jan. 2018.

ARENDT, Hannah. A Condição Humana. Tradução de Roberto Raposo. 10ª ed. Rio de Janeiro: Forense Universitária, 2009.

BAUMAN, Zygmunt. Tempos Líquidos. Tradução Carlos Alberto Medeiros. Rio de Janeiro: Jorge Zahar Editor, 2007.

BARBOSA, Wilmar do Valle. Tempos Pós-Modernos. In: LYOTARD, Jean-François. O Pós-moderno. Tradução Ricardo Corrêa Barbosa. $3^{a}$ edição. Rio de Janeiro: Jose Olympio Editora, 1988.

BLYTH, Mark. Austeridade: a história de uma ideia perigosa. Tradução de José Antônio Freitas e Silva. São Paulo: Autonomia Literária, 2017.

BRESSER-PEREIRA, Luiz Carlos. Salvar o euro ou salvar a Europa. Folha de São Paulo, São Paulo, 07 mai. 2012. Disponível em:<http://www.bresserpereira.org.br/documento/4925>. Acessado em 25 jan. 2019. 
BROWN, Wendy. Revisando Foucault: homo politicus e homo o economicus. In . Undoing the Demos: Neoliberalism's Stealth Revolution. Tradução de Danielle Guizzo Archela, Gustavo Hessmann Dalaqua e Sibele Paulino. Nova lorque: Zone Books / MIT Press, 2015.

BRUNKHORST, Hauke. A Decapitação do Legislador: a crise europeia - paradoxos da constitucionalização do capitalismo democrático. Tradução Pablo Holmes. Revista Direito.Unb, Brasília, v. 01, n. 01, p. 93-118, jan-jun 2014.

BUGARIC, Bojan. Europe Against the Left? On Legal Limits to Progressive Politics. London School of Economics and Political Science, London, 'Europe in Question' Discussion Paper Series, n. 61, mai. 2013. Disponível em:<http://eprints.Ise.ac.uk/53186/1/LEQSPaper61.pdf>. Acessado em 25 jan. 2019.

CHAUÍ, Marilena. Multilateralismo. In: Seminário Internacional. Ameaças à Democracia e a Ordem Multipolar. Fundação Perseu Abramo. 14 set. 2018. Rio de Janeiro. Disponível em:<https://www.youtube.com/watch?v=GsuQIAwImsU>. Acessado em 25 jan. 2019.

CLARK, Giovani; CORREAA, Leonardo Alves; NASCIMENTO, Samuel Pontes do. A Constituição econômica entre a efetivação e os bloqueios institucionais. Revista da Faculdade de Direito da Universidade Federal de Minas Gerais, n. 71, p. 677-700, jul./dez. 2017.

DARDOT, Pierre; LAVAL, Christian. Néolibéralisme et Subjetcitvation Capitaliste. Revista Cités, Paris, n. 41, p. 35-50, 2010. Disponível em:<https://www.cairn.info/revue-cites-2010-1-page-35.htm>. Acessado em 25 jan. 2019.

DWECK, Esther; OLIVEIRA, Ana Luíza Matos; ROSSI, Pedro Rossi (coord.). Austeridade e Retrocesso: Impactos Sociais na Política Fiscal no Brasil. São Paulo: Brasil Debate e Fundação Friedrich Ebert, vol. 1, ago. 2018.

FOUCAULT, Michel. Nascimento da Biopolítica: curso dado no Collège de France (1978-1979). Tradução de Eduardo Brandão. São Paulo: Martins Fontes, 2008.

HEINEN, Luana Renostro. A Análise Econômica do Direito de Richard Posner e os pressupostos irrealistas da economia neoclássica. Anais do CONPEDI, Direito e Economia, 2012. Disponível em:<http://www.publicadireito.com.br/artigos/?cod=991c0955da231335>. Acessado em 24 jan. 2019.

JESSOP, Bob. The Heartlands of Neoliberalism and the Rise of the Austerity State. In SPRINGER, S.; BIRCH, K. and MacLeavy, J. (ed.). Handbook of Neoliberalism. London: Routledge, 2016. Disponível em:<http://eprints.lancs.ac.uk/84712/1/F_2016d_Neoliberalism_Heartlands_Preprint.pdf >. Acessado em 25 jan. 2019.

KREUDER-SONNEN, Christian. Beyond Integration Theory: The (Anti-)Constitutional Dimension of European Crisis Governance. Journal of Common Market Studies, 
Oxford (UK), volume 54, n. 6, p. 1350-1366, nov. 2016. Disponível em:<https://onlinelibrary.wiley.com/doi/full/10.1111/jcms.12379>. Acessado em 11 jan. 2019.

KRUGMAN, Paul. "Como a defesa da austeridade se desfez". Tradução Mario Zamarian. New York Review of Books/Valor Econômico, edição digital, 14 jun 2013. Disponível em: <http://reformadagestaopublica.org.br/view.asp?cod=5370>. Acesso em: 24 jan. 2019.

KUHN, Thomas S. A Estrutura das Revoluções Científicas. Tradução Beatriz Vianna Boeira e Nelson Boeira. São Paulo: Editora Perspectiva, 1998.

KUO, Ming-Sung. The Moment of Schmittian Truth: Conceiving of the State of Exception in the Wake of the Financial Crisis. In: Christian Joerges and Carola Glinski (eds), The European Crisis and the Transformation of Transnational Governance: Authoritarian Managerialism versus Democratic Governance. Oxford: Hart, 2014. Disponível em:<https://papers.ssrn.com/sol3/papers.cfm?abstract_id=2400386>. Acessado em 23 jan. 2019.

LYOTARD, Jean-François. O Pós-moderno. Tradução Ricardo Corrêa Barbosa. $3^{a}$ edição. Rio de Janeiro: Jose Olympio Editora, 1988.

MUMFORD, Lewis. A Cidade na História: suas origens, transformações e perspectivas. Tradução Neil R. da Silva. 4ª edição. São Paulo: Martins Fontes, 1998.

NEWMAN, Abraham. Austerity and the End of the European Model: How Neoliberals Captured the Continent. Foreign Affairs, edição digital, 01 mai. 2012. Disponível em:<https://www.foreignaffairs.com/articles/europe/2012-05-01/austerity-and-endeuropean-model>. Acessado em 24 jan. 2019.

NUNES, António José Avelãs. A Crise Atual do Capitalismo: capital financeiro, neoliberalismo, globalização. São Paulo, Revista dos Tribunais, 2012.

. O Euro: das promessas do paraíso às ameaças de austeridade perpétua.

Boletim de Ciências Econômicas, Faculdade de Direito da Universidade de Coimbra, Coimbra, n. LVI, p. 3-166, 2013.

PINTO, Paulo Ribeiro. Recessão grega três vezes mais destrutiva que em Portugal. Revista Dinheiro Vivo, edição digital, 19 ago. 2018. Disponível em:<https://www.dinheirovivo.pt/internacional/recessao-grega-tres-vezes-maisdestrutiva-que-em-portugal/>. Acessado em 25 jan. 2019.

RODGERS, Lucy, STYLIANOU, Nassos. Em números: Como a crise piorou a vida dos gregos. Revista BBC News, edição digital, 18 jul. 2015. Disponível em:<https://www.bbc.com/portuguese/noticias/2015/07/150716_situacao_grecia_rb>. Acessado em 25 jan. 2019.

SANTOS, Boaventura de Sousa. A Difícil Democracia: reinventar as esquerdas. São Paulo: Boitempo, 2016. 
SOUZA, Washington Peluso Albino de. Primeiras Linhas de Direito Econômico. São Paulo: LTR, 2017.

WHITE, Jonathan. Emergency Europe. Revista Political Studies, London, vol. 63, p. 300-318, 2015.

WILKINSON, Michael A. The Specter of Authoritarian Liberalism: Reflections on the Constitutional Crisis of the European Union. German Law Journal, Frankfurt, vol. 14, n. 5, 2013. Disponível em:<http://www.germanlawjournal.com/volume-14-no-05/>. Acessado em 24 jan. 2019.

ECONOMIA portuguesa cresceu 2,1\%, abaixo das previsões do Governo. Revista Observador, edição digital, 14 fev. 2019. Disponível em:<https://observador.pt/2019/02/14/ine-crescimento-economico-portugues-cresceu21-em-2018/>. Acesso em 25 abr. 2019.

Recebido em 31/05/2019 Aprovado em 07/10/2019 Received in 31/05/2019 Approved in 07/10/2019 